\title{
Gestão estratégica de pessoas no setor público: percepções de gestores e funcionários acerca de seus limites e possibilidades em uma autarquia federal
}

\author{
Luana Jéssica Oliveira Carmo \\ Centro Federal de Educação Tecnológica de Minas Gerais (Cefet-MG) \\ Lilian Bambirra de Assis \\ Centro Federal de Educação Tecnológica de Minas Gerais (Cefet-MG) \\ Mariana Geisel Martins \\ Centro Federal de Educação Tecnológica de Minas Gerais (Cefet-MG) \\ Cristina Camila Teles Saldanha \\ Fundação João Pinheiro(FJP-MG) \\ Patrícia Albuquerque Gomes \\ Centro Federal de Educação Tecnológica de Minas Gerais (Cefet-MG)
}

A gestão de pessoas no setor público vivenciou profundas transformações, principalmente após a década de 1990, quando adota uma perspectiva estratégica orientada para resultados. Tais modelos enfrentam desafios de implantação devido às características inerentes à administração pública, como a burocracia e impessoalidade. Assim, torna-se relevante analisar o impacto dessas mudanças na dinâmica interna de organizações públicas. Desse modo, o objetivo deste trabalho foi analisar a percepção e atitudes de gestores e funcionários acerca da gestão de pessoas em uma autarquia federal. $O$ estudo consistiu na aplicação e análise de entrevistas semiestruturadas e de técnicas de construção de desenhos. Os resultados apontaram para a ausência de um modelo estratégico de gestão de pessoas, devido a características peculiares do setor público representadas subjetivamente através dos desenhos produzidos. Para estudos futuros, sugere-se a ampliação da utilização da técnica de construção de desenhos para análise de percepções e atitudes no âmbito do setor público.

Palavras-chave: gestão de pessoas - administração estratégica, gestão por competência, administração federal - Brasil, administração por objetivos, avaliação de desempenho, burocracia, impessoalidade

[Artigo recebido em 15 de janeiro de 2017. Aprovado em 22 de novembro de 2017.] 
Gestión estratégica de personas en el sector público: percepciones de gestores y funcionarios acerca de sus límites y posibilidades en una autarquía federal

Lagestión depersonas en el sector público ha experimentado profundastransformaciones, principalmente después de la década de 1990, cuando adopta una perspectiva estratégica orientada hacia resultados. Tales modelos enfrentan desafíos de implantación debido a las características inherentes a la administración pública, como la burocracia e impersonalidad. Así, resulta relevante analizar el impacto de estos cambios en la dinámica interna de las organizaciones públicas. De este modo, el objetivo de este trabajo fue analizar la percepción y actitudes de gestores y funcionarios acerca de la gestión de personas en una autarquía federal. El estudio consistió en la aplicación y análisis de entrevistas semiestructuradas y de técnicas de construcción de dibujos. Los resultados apuntaron a la ausencia de un modelo estratégico de gestión de personas, debido a características peculiares del sector público representadas subjetivamente a través de los dibujos producidos. Para estudios futuros, se sugiere la ampliación de la utilización de la técnica de construcción de dibujos para el análisis de percepciones y actitudes en el ámbito del sector público.

Palavras Chave: gestión de personas - administración estratégica, gestión por competências, administración federal - Brasil, administración por objetivos, evaluación del desempeño, burocracia, impersonalidad

Strategic people management in the public sector: perceptions of managers and employees about their limits and possibilities in a federal autarchy

The management of people in the public sector has undergone profound transformations, mainly after the 1990s, when it adopts a strategic perspective oriented to results. Such models face implementation challenges because of inherent characteristics of public administration, such as bureaucracy and impersonality. Thus, it is relevant to analyze the impact of these changes on the internal dynamics of public organizations. In this way, the objective of this work was to analyze the perception and attitudes of managers and employees about the management of people in a federal autarchy. The study consisted of the application and analysis of semi structured interviews and drawing construction techniques. The results indicated the absence of a strategic model of people management, due to the peculiar characteristics of the public sector subjectively represented through the drawings produced. For future studies, it is suggested to extend the use of the technique of construction of drawings to analyze perceptions and attitudes within the public sector.

Keywords: management of people - strategic administration, competence management, federal administration - Brazil, management by objectives, performance evaluation, bureaucracy, impersonality 


\section{Introdução}

Diante das transformações no cenário mundial, a globalização e o avanço tecnológico, o setor público no Brasil vem sendo forçado a se adaptar às mudanças organizacionais que envolvem a redefinição de seus aspectos estratégicos (Antonello; PAntoja, 2010). A tentativa do Estado em acompanhar a evolução dos modelos de gestão pode ser compreendida pela definição de três períodos da gestão pública: o Estado patrimonial, o burocrático e o gerencial (BLONSKI et al., 2017; BRESSER-PEREIRA, 1998). Entretanto, a administração pública carrega traços de cada um dos três períodos em seus modelos de gestão, tornando o setor público um ambiente complexo e desafiador para a gestão de pessoas (SCHIKMANN, 2010).

Baseada na Nova Gestão Pública (New Public Management - NPM), a perspectiva gerencialista propõe um serviço público mais flexível, descentralizado, eficiente, de melhor qualidade e orientado ao cidadão, aproximando-se do setor privado (BResser-PereirA, 1998; CostA, 2008; Peters, 2008). Após as mudanças pretendidas pelas reformas gerencialistas, principalmente na década de 1990, os dirigentes passaram a lidar com muitos paradoxos, relacionados à transformação contínua das organizações (BARBIERI, 2012). Esses paradoxos estimularam estudos relacionados a estilos de liderança, estrutura organizacional, medidas de desempenho, administração de recursos humanos, tecnologia, cultura e estratégia no setor público (e.g. SAlles; VilLARDI, 2017; NASCIMENTO; EMENDOERFER; Gava, 2014; MOURA; SOUZA, 2016).

No âmbito da gestão de pessoas, a perspectiva gerencialista almeja um estilo de gestão semelhante ao da iniciativa privada (NogueIRA; SANTANA, 2015). Para isso, é necessário que o gestor público tenha a capacidade de alinhar os funcionários à estratégia da organização e de governo, de forma que os esforços sejam capazes de gerar resultados concretos para o cidadão. Dessa forma, a atual gestão de recursos humanos $(\mathrm{RH})$ passa a assumir um papel estratégico dentro da organização, tendo ainda o dever de se atentar ao desempenho dos recursos humanos direcionando-os para os resultados (LONGO, 2007).

Seguindo esses direcionamentos, este estudo propõe avançar na literatura já existente sobre os desafios da gestão estratégica de pessoas no setor público. Pretendeu-se compreender a percepção de gestores e funcionários acerca do modelo de gestão de pessoas adotado em uma autarquia federal. A pesquisa utiliza uma abordagem qualitativa, por meio da aplicação de entrevistas semiestruturadas em combinação com métodos visuais de pesquisa, relativos à construção e interpretação de desenhos elaborados pelos entrevistados. Essa técnica buscou 
acessar aspectos simbólicos das percepções e atitudes dos entrevistados em relação à gestão de pessoas da autarquia, sendo complementada pela análise das entrevistas (VERGARA, 2005).

\section{Fundamentos teóricos}

É de fundamental importância destacar as principais características e reformas institucionais ocorridas no decorrer dos anos relacionadas à administração pública, em uma breve descrição histórica desde as reformas de 1930 até a década de 1990, com o surgimento da administração gerencial.

\section{Modelos de gestão pública e reformas estatais no contexto brasileiro}

A administração pública brasileira sofreu inúmeras transformações até os dias de hoje. Conforme Costa (2008), as modernizações das estruturas da gestão pública ganharam destaque com a Revolução de 1930. A nova dinâmica de instauração da modernidade, com a separação entre Estado e mercado e criação de novas instituições deram abertura à sua racionalização.

Isso representou a ruptura com o patrimonialismo. A administração patrimonialista decorre das monarquias absolutistas, em que não havia a distinção entre o patrimônio público e o privado, pois o Estado era compreendido enquanto propriedade do rei. As práticas como nepotismo e corrupção eram respaldadas. Com o desenvolvimento do capitalismo industrial e a emergência das democracias parlamentares, o modelo patrimonialista se tornou incompatível devido à necessidade de separar o Estado do mercado. Além da separação entre público e privado, era necessário um distanciamento entre o político e o administrador público (BRESSER-PEREIRA, 1996).

A emergência de uma administração pública burocrática, "adotada para substituir a administração patrimonialista" (BRESSER-PEREIRA, 1996, p. 10), foi pautada no modelo weberiano de padronização e rigidez administrativa, que trazia em seus ideais a concepção de carreiras, a profissionalização, a hierarquia, a impessoalidade e o formalismo. A criação do Departamento Administrativo do Serviço Público (Dasp) na década de 1930 foi um marco para a reforma burocrática e visou à "revolução modernizadora do país, industrializá-lo e valorizar a competência técnica" (Bresser-Pereira, 2001, p. 11). O Dasp buscou concretizar os princípios de racionalidade e eficiência, tornando-se a grande agência de modernização do Estado à sua época.

Entretanto, com a queda do Governo Vargas, o Dasp perdeu grande parte de suas atribuições. Segundo Bresser-Pereira (2001), a reforma não respondia às reais 
necessidades da sociedade e política brasileira. O modelo burocrático apresenta suas disfunções, como a rigidez das normas que inibem as transformações e desestimulam inovações, já que não é um modelo flexível (COSTA, 2008).

Em 1967, a Reforma Administrativa criada pelo Decreto-lei no 200 no Brasil configurou-se como uma tentativa de abandono à rigidez burocrática e adoção da modernização nos processos administrativos do Estado brasileiro. Uma parte significativa das atividades públicas foi transferida para fundações, autarquias e sociedades de economia mista, a fim de promover maior descentralização do Estado (nesse período houve a separação entre administração direta e indireta). A administração pública foi orientada por princípios modernos de gestão e pela definição de funções administrativas básicas, tais como o planejamento, gestão do orçamento, serviços gerais, recursos humanos e finanças (CASTOR; JOSÉ, 1998).

No início dos anos 1970, houve uma nova tentativa de estímulo à modernização com a criação da Secretaria de Modernização e Reforma Administrativa (Semor), encarregada de implantar técnicas de gestão, tais como a administração de recursos humanos e a modernização funcional e estrutural. Porém, limitada aos processos internos federais e não mais atuando junto aos estados e municípios juntamente com a Secretaria de Articulação com Estados e Municípios, a Semor teve sua atuação reduzida (CASTOR; JOSÉ, 1998).

A redemocratização do Estado, marcada pela criação da Constituição de 1988, trouxe reformas administrativas em busca da reconstrução do Estado como um agente mais efetivo e eficiente. Entretanto, a Constituição de 1988 configurou-se como um retrocesso na modernização da gestão pública brasileira, pois reduziu a flexibilidade da administração indireta ao lhe atribuir normas de funcionamento iguais às da administração direta. Além disso, o Poder Executivo perdeu autonomia em relação aos órgãos públicos e houve a imposição de um Regime Jurídico Único aos servidores dos municípios, estados e União, transformando o regime de trabalho de empregados celetistas para estatutários (BRESSER-PEREIRA, 1996; COSTA, 2008).

Com a necessidade de certa flexibilidade e amenizando a rigidez burocrática, surge, na década de 1990, a administração gerencial, voltada para o desenvolvimento de uma cultura gerencial nas organizações (BRESSER-PEREIRA, 2001; COSTA, 2008). As reformas do aparelho estatal brasileiro nesse período seguiram as linhas do New Public Management (NPM) ou Nova Gestão Pública, que buscava a superação do modelo burocrático por meio da perspectiva gerencialista. Essa abordagem centrava-se basicamente na adaptação e transferência dos conhecimentos gerenciais desenvolvidos no setor privado para o setor público (Pecl; Pieranti; Rodrigues, 2008; Peters, 2008; Cavalcante, 2010). 
Segundo Costa (2008), essas reformas objetivaram a redefinição do papel do Estado, deixando de ser prestador de serviços e reforçando sua postura de regulador e provedor desses serviços. Nessa nova perspectiva, caminhava-se para uma administração pública gerencial, mais flexível e eficiente, voltada para o atendimento da cidadania, tendo que modificar tanto o plano institucional-legal, quanto o plano cultural e de gestão, para atingir seus objetivos. A administração pública gerencial transmite autonomia ao administrador na gestão de recursos humanos, que começa a ser visto como importante na geração de resultados (COSTA, 2008).

Mais recentemente, houve a introdução de aspectos estratégicos à gestão de pessoas com os Decretos no 5.707/2006 e no 7.133/2010. O Decreto no 5.707/2006 traz à administração pública brasileira a instituição de planos de desenvolvimento de pessoal a serem implementados pelos órgãos e instituições da administração pública federal. O decreto teve como intuito a melhoria da eficiência e qualidade dos serviços prestados ao cidadão por meio do desenvolvimento permanente de servidores públicos e adequação de suas competências às estratégias de governo, por meio de ações racionais e efetivas de capacitação. O Decreto no 7.133/2010, por sua vez, aprova critérios e procedimentos para a realização de avaliações de desempenho individuais e institucionais, com o intuito de inserir a gestão por resultados no setor público federal.

É importante ressaltar, nessa retomada histórica, que ainda hoje é possível identificar na gestão pública vários traços de todos os modelos de gestão. Secchi (2009, p. 365) reflete sobre a necessidade de se desvincular do discurso de ruptura de modelos e de se adotar a ideia de "processo cumulativo de mudanças nas práticas e valores". A administração pública brasileira passa a sofrer com a rigidez burocrática, concomitante com traços patrimonialistas não superados, o que resulta em alto custo e baixa qualidade no setor público, contrariando o discurso de eficiência disseminado pelo regime burocrático. Com a chegada dos anos 1970, a administração pública burocrática se vê em crise, e valores advindos da administração de empresas, como descentralização e flexibilidade, atingem o setor público. É o advento da administração gerencial (BRESSER-PEREIRA, 1996). Essa nova forma de gestão pública influencia as práticas direcionadas aos recursos humanos, que passam a ser vistos como ativos essenciais para atingir os objetivos institucionais. O próximo tópico descreve as principais práticas de gestão de pessoas no setor público. 


\section{Práticas de gestão de pessoas no setor público}

As práticas de recrutamento e seleção no setor público têm o foco no cargo e não em competências. A forma ampla em que os cargos são descritos faz com que as competências não sejam aproveitadas. Essa descrição dos cargos para concursos limita a atuação dos funcionários de acordo com suas competências (SCHIKMANN, 2010).

Em relação às práticas de gestão de pessoas, há uma concentração em torno da gestão do desempenho no setor público. Para Schikmann (2010), a política de avaliação de desempenho possui um papel importante para o desenvolvimento de uma cultura voltada para resultados, já que o alinhamento de objetivos individuais e das equipes às metas da organização implica o maior envolvimento dos funcionários de todos os níveis, os quais passam a se sentir pessoalmente responsáveis pelo desempenho da organização. Conforme Barbosa (1996), a questão da meritocracia e da sua avaliação é polêmica para toda a teoria da administração moderna, e o problema está relacionado à forma com que a situação é tratada, normalmente com a criação de decretos, ou outros mecanismos jurídicos e formais.

Integrada à questão do desempenho, tem-se a gestão da compensação. A gratificação de desempenho continua a ser uma estratégia adotada para recompor salários, e não para recompensar o alcance ou superação de desempenhos esperados; profissionais que ocupam cargos de direção ou em comissão continuam a receber gratificação sem que seu desempenho individual seja avaliado (ODELIUS; SANTOS, 2007). Nas organizações públicas, a gratificação é utilizada como forma improvisada de compensação à impossibilidade de aumento salarial. Tal fator constitui uma deformação da verdadeira função da gratificação, que foi criada para contemplar funções desempenhadas que apresentam algum risco ou esforço adicional aos previstos na execução da maior parte das tarefas da organização (SCHIKMANN, 2010).

Em relação à capacitação, Shickmann (2010) afirma que deve ocorrer de forma contínua. É essencial para desenvolver um quadro com as competências requeridas pela organização. Porém, o setor público, mesmo sendo intensivo em conhecimento, ainda não possui uma cultura e um ambiente voltados para a aprendizagem organizacional e/ou para a inovação e, com raras exceções, também não incentiva a educação continuada de seus servidores (COELHO, 2004). Essas práticas de gestão de pessoas no setor público devem ser modificadas, caso seja adotado um modelo de gestão estratégica de pessoas no setor público, conforme proposto pelo próximo tópico. 


\section{Gestão para resultados: o modelo de gestão estratégica de pessoas no setor público}

Longo (2007) aponta uma alteração nas relações de trabalho ao longo dos anos. No lugar da estabilidade, a aprendizagem e desenvolvimento passaram a ocupar o principal aspecto de interesse dos trabalhadores. Para o autor, com essas alterações, a área de gestão de pessoas passou a desempenhar uma função estratégica nas instituições, de relevância para o alcance dos objetivos organizacionais (LoNGo, 2007).

Com essas mudanças, surgem modelos de gestão orientados para resultados, adotados primeiro pela iniciativa privada e, posteriormente, no setor público. Nesse contexto, a gestão de pessoas passa a assumir uma dimensão estratégica, ao ser vista como uma vantagem competitiva para as organizações. A gestão estratégica de pessoas considera os indivíduos como ativos valiosos devido a certas competências úteis, conferindo à organização uma "vantagem competitiva" (MASCARENHAS, 2008, p. 7).

Para Schikmann (2010), o desempenho de uma organização está condicionado às pessoas que nela atuam, por isso, o planejamento estratégico deve abranger desde o nível macro até o individual. No contexto da administração pública, a autora apresenta como instrumentos de gestão estratégica de pessoas o planejamento de recursos humanos, a gestão por competências, a capacitação continuada com base em competências e a avaliação de desempenho fundada em competências.

Longo (2007) aborda o dilema da gestão estratégica no setor público afirmando que a ambiguidade existente nesse setor dificulta a precisão da definição da estratégia. As mudanças no cenário político interferem nas estratégias das organizações, tanto públicas quanto privadas. Assim, as forças ambientais constituem-se em uma variável importante para a definição de estratégias, já que influenciam a eficácia organizacional (SILVA; MELLO, 2011).

Desse modo, para Longo (2007), esse dilema representa a manifestação da complexidade que caracteriza a gestão pública. $O$ autor sugere a tentativa de influenciar a conduta das pessoas na busca de adequá-la aos objetivos de uma organização. Assim, ele apresenta o modelo da Figura 1, onde os resultados dependem da conduta das pessoas, e esta, por conseguinte, depende da vontade e das competências dessas pessoas. 
Figura 1 - A gestão de recursos humanos (GRH)

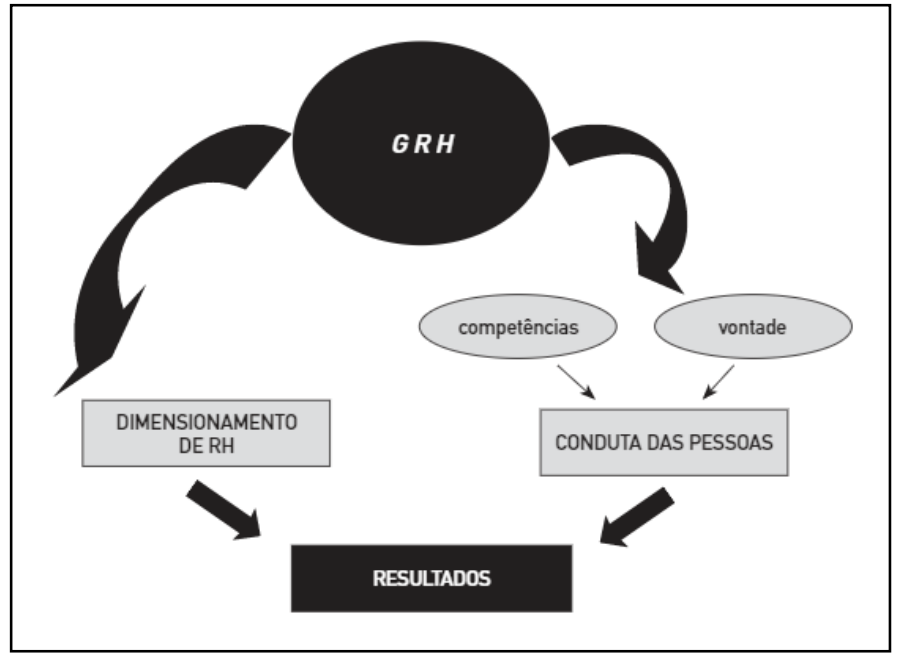

Fonte: Longo (2007).

Amaral (2006) considera que a gestão por competências é relativamente recente e complexa, e, por isso, tem contribuído para a manutenção das incertezas quanto à sua aplicabilidade ao setor público brasileiro. O Decreto no 5.707/2006 conceitua gestão por competências como:

[...] gestão por competência: gestão da capacitação orientada para o desenvolvimento do conjunto de conhecimentos, habilidades e atitudes necessárias ao desempenho das funções dos servidores, visando ao alcance dos objetivos da instituição (BRASIL, 2006).

\section{A gestão por competências e o contexto específico do setor público}

A gestão por competências no setor público implica em um enfoque amplo e integrador, considerando conhecimentos técnicos e outras características pessoais. As competências englobam as habilidades interpessoais, as capacidades cognitivas e de conduta, o conceito ou percepção de si próprio, traduzido em atitudes e valores, os motivos ou estímulos que selecionam e orientam a conduta, e os traços de personalidade ou caráter (AMARAL, 2006).

O foco do Decreto $n^{\circ} 5.707 / 2006$ é a capacitação e o direcionamento de esforços para a aprendizagem contínua nas instituições, de forma a impactar o desenvolvimento de competências individuais e institucionais (SILVA; MELLO, 2013). Entretanto, conforme os autores, o maior desafio está relacionado à mudança cultural no serviço público, sendo necessário comprometimento e ação de gestores 
e servidores públicos. A implantação da gestão por competências no setor público exige mudanças organizacionais profundas, a começar pela reestruturação da área de $\mathrm{RH}$ e um mapeamento de competências requeridas.

Assim, as práticas relacionadas à gestão por competências, como as carreiras sem fronteiras, a flexibilidade e a descentralização, são consideradas incompatíveis com o atual ambiente organizacional das organizações públicas. Essa incompatibilidade ocorre devido aos traços da burocracia e ao modelo tradicional de gestão de pessoas, focado no cargo e não no indivíduo (AMARAL, 2006). Com isso, torna-se relevante analisar a percepção e atitudes de gestores e funcionários acerca da gestão de pessoas em uma autarquia federal, buscando verificar como essa ocorre na prática.

\section{Procedimentos metodológicos}

Devido à natureza do estudo, a metodologia adotada foi de natureza descritiva qualitativa. A pesquisa descritiva aborda o registro, a análise e a interpretação de um fenômeno. A pesquisa qualitativa é aberta, flexível e focaliza a realidade de forma complexa, adequando-se a cada contexto (LAKATOS; MARCONI, 2011). Quanto ao recorte temporal, a pesquisa adotou o recorte transversal, em que os dados são coletados em um ponto no tempo (RICHARDSON, 1999).

A coleta de dados foi feita por meio de entrevistas semiestruturadas. Essa modalidade de pesquisa é reconhecida pela flexibilidade e oportunidade de avaliar atitudes e comportamentos do entrevistado, possibilitando a coleta de dados importantes que não se encontram em fontes documentais (LAKATOS; MARCONI, 2011).

Foram entrevistados 10 líderes (o que corresponde à totalidade dos líderes ativos no período da coleta) ocupantes de cargos de direção, gerência, assessoria, presidência e vice-presidência; e 5 funcionários (técnicos e auxiliares) de diferentes setores, com diferentes tempos de casa. A técnica de amostragem utilizada foi do tipo não probabilística intencional, ou seja, a amostra foi escolhida propositalmente, por possuir características que se constata serem relevantes para a compreensão de um fenômeno (GOODE; HATT, 1979). Com essa técnica de amostragem, o pesquisador tem liberdade de escolha, dirigindo-se a grupos de forma intencional para saber a opinião dos membros (BARROS; LEHFELD, 1997).

O critério utilizado para a escolha dos sujeitos da pesquisa teve como objetivo privilegiar líderes e uma pequena amostra de funcionários. A escolha sobre a quantidade de entrevistados levou em consideração o objetivo do trabalho, que foi analisar a percepção de gestores e funcionários acerca da gestão de pessoas em uma autarquia federal, não tendo como interesse alcançar um nível 
de saturação das respostas, mas sim dar abertura a diferentes percepções ao dividir os entrevistados em dois grupos-chave: pessoas com cargos de chefia e funcionários.

As entrevistas semiestruturadas foram realizadas pessoalmente entre os meses de novembro e dezembro de 2013, na sede da autarquia estudada, de forma individual. Foram desenvolvidos dois roteiros de entrevistas: um direcionado aos líderes; outro, aos funcionários. Para ambos os grupos (líderes e funcionários) havia perguntas iniciais, com o intuito de saber alguns dados do entrevistado que poderiam ser relevantes para a pesquisa, como idade, cargo atual, principais atividades no cargo atual, há quanto tempo trabalha na autarquia e no cargo atual. Era solicitado também que o entrevistado falasse sobre sua trajetória pessoal, com o direcionamento sobre quais outros lugares trabalhou e qual era a função exercida. O Quadro 1 apresenta especificamente quais questões foram abordadas nas entrevistas, considerando cada grupo. 


\section{Quadro 1 - Questões abordadas nas entrevistas}

\author{
Perguntas para Grupo I: Líderes \\ 1 - O que você entende por gestão \\ estratégica de pessoas?
}

2 - Quais as principais características da gestão de pessoas da autarquia? 0 que tem de diferente dos outros órgãos/ entidades do setor público?

3 - Quais as alterações ocorridas na gestão de pessoas da entidade nos últimos anos? O que mudou? Quando?

4 - Você considera o fato de ser uma autarquia um aspecto facilitador para o $\mathrm{RH}$ estratégico ou para a gestão como um todo ao comparar com outros órgãos/entidades do setor público?

5 - Existe alguma limitação em relação às práticas de $\mathrm{RH}$ por se tratar de uma entidade do setor público? (Gentileza considerar aspectos como recrutamento, seleção, treinamento, cargos, salários e carreiras, demissão.)

6 - Existe um modelo de gestão por competências?

7 - Existem mecanismos de valorização das competências dos funcionários?

8 - Qual o principal desafio da gestão (geral) atualmente? E os desafios relacionados à gestão de pessoas?

9 - O que você mudaria em relação à gestão de pessoas da entidade?

\section{Perguntas para Grupo II: Funcionários}

1 - Construção de desenhos: como você se sente em relação à gestão de pessoas da autarquia?

2 - O que você entende por gestão estratégica de pessoas?

3 - Você percebe diferença entre as práticas de $\mathrm{RH}$ aqui e de outros locais em que já trabalhou? Em que aspectos?

4 - Quais as alterações ocorridas na gestão da entidade nos últimos anos? O que mudou para você? Quando?

5 - Existe alguma limitação em relação às práticas de $\mathrm{RH}$ por se tratar de uma entidade do setor público? (Considerar aspectos como recrutamento, seleção, treinamento, cargos, salários e carreiras, demissão.)

6 - Existe um modelo de gestão por competências na autarquia?

7- Você considera que existem mecanismos de valorização das competências dos funcionários?

8 - Você sente que existe flexibilidade em relação às sugestões e ideias dos funcionários?

9 - Você se sente mais cobrado em relação à suas tarefas ou em relação à sua competência?

10 - Qual o principal desafio que você percebe em relação à gestão (geral) da entidade atualmente? $E$ os desafios relacionados à gestão de pessoas?

11 - O que você mudaria em relação à gestão de pessoas da entidade? 
Ademais, também foi utilizada como técnica de coleta de dados a construção de desenhos pelos funcionários entrevistados. Essa técnica teve o objetivo de instigar a manifestação de aspectos emocionais e psicológicos dos entrevistados, em dimensões não alcançadas pelas palavras (VERGARA, 2005). Optou-se pela construção de desenhos não estruturada com o intuito de transmitir ao entrevistado liberdade para desenhar o que queria (VERGARA, 2005). Não foi delimitado um tempo para a construção dos desenhos, de modo a reforçar a liberdade oferecida a ele. Os desenhos foram coletados de forma individual, no início das entrevistas com os funcionários. Os entrevistados foram convidados a interpretar seus desenhos, o que contribuiu para a análise dos dados.

Para analisar os dados, foi utilizada a análise de conteúdo. Bardin (2002, p. 42) define a análise de conteúdo como "conjunto de técnicas de análise das comunicações visando obter, por procedimentos sistemáticos e objetivos, indicadores que permitam a inferência de conhecimentos relativos às mensagens." Ela funciona como um leque de apetrechos, podendo ser uma via de análise dos significados ou dos significantes, e possui uma função heurística, enriquecendo assim a pesquisa exploratória, por meio da descoberta. Para a autora, a análise de conteúdo caminha entre dois polos - entre o rigor da objetividade e a fecundidade da subjetividade. O investigador se atrai pelo oculto, o latente, o não aparente, o potencial inédito (não dito) presente em qualquer mensagem (BARDIN, 2002). A análise de dados seguiu as três etapas descritas por Bardin (2002): 1ạ) préanálise; 2â) exploração do material; e 3a) tratamento dos resultados, inferência e interpretação.

Diante da necessidade de atualização dos dados, considerando que os dados foram coletados em 2013, num recorte transversal, optou-se por fazer uma observação participante e análise documental. Essa atualização ocorreu nos meses de setembro e outubro de 2016 com o objetivo de analisar se houve mudanças significativas na gestão de pessoas da autarquia desde a pesquisa feita em 2013.

\section{Descrição da autarquia}

A autarquia federal objeto de estudo deste trabalho foi criada por meio de um Decreto-Lei em 1946. De acordo com dados disponíveis no portal da transparência de tal entidade, ela possui 87 funcionários, $48 \%$ do sexo feminino, e $52 \%$ do sexo masculino. Em relação aos cargos de chefia, 23\% são do sexo feminino, e $77 \%$ do sexo masculino. A faixa etária predominante é de 36 a 60 anos (73,56\%), e 31\% dos funcionários possuem acima de 20 anos de trabalho na autarquia. Em relação ao nível de escolaridade dos funcionários, considerando também os gestores, 40,23\% possuem ensino superior completo. 
Sobre a gestão de pessoas da autarquia, a forma de recrutamento utilizada atualmente é o concurso público, entretanto, nem sempre foi assim. Desde sua fundação, a forma de recrutamento variou entre períodos em que era obrigatório passar por provas e outros em que se utilizava a indicação, sem concurso público. Com isso, vários funcionários ingressaram na autarquia sem passar pelo concurso.

O regime de contratação segue as normas celetistas, entretanto, existe uma discussão há alguns anos sobre se tornar RJU (Regime Jurídico Único). Em relação às práticas de gestão de pessoas na entidade pesquisada, tem-se a avaliação de desempenho, a pesquisa de clima e o levantamento de necessidades de treinamento (LNT), que possuem periodicidade anual. Além disso, foi criado em 2009 o Plano de Cargos, Carreiras e Salários (PCCS). No PCCS, é apresentado o enquadramento da faixa salarial de acordo com os níveis, bem como a gratificação paga aos ocupantes de cargos comissionados.

A entidade não possui um planejamento estratégico formal. Possui missão, visão e políticas de qualidade, o que foi criado com as exigências para a certificação da norma ISO 9001. Anualmente é criado um plano de trabalho que direciona quais serão as ações referentes ao próximo ano para cada setor. No período da coleta de dados (2013-2016), houve uma troca de presidência. Essa troca é feita de quatro em quatro anos, por meio de eleição. São elegíveis os representantes que fazem parte da categoria profissional a qual a entidade fiscaliza.

\section{Análise e discussão de resultados: a gestão de pessoas pela ótica dos funcionários}

A metodologia de pesquisa consistiu na aplicação de entrevistas, observação participante e na construção de desenhos pelos entrevistados. O desenho deveria ilustrar como o funcionário se sentia em relação à gestão de pessoas da autarquia. Para discussão dos resultados, os entrevistados são identificados, no decorrer da análise dos dados, como E1, E2, até o E15, sendo que o intervalo compreendido de E1 a E10 corresponde aos líderes, e de E11 a E15, aos funcionários entrevistados.

Como primeiro aspecto notado na pesquisa, destaca-se que o desenho do funcionário entrevistado com menos tempo de casa possui uma visão alinhada ao funcionário com mais tempo de casa. O entrevistado 14 (E14) está há 40 anos na autarquia, é aposentado e continua trabalhando na organização. Já o entrevistado E15 tem menos de um ano na entidade e já compartilha da mesma impressão que o entrevistado E14 em relação à gestão de pessoas da entidade, o que pode ser visto pelos desenhos: 
Figura 2 - Desenho do entrevistado 14

Ao interpretar o desenho, o funcionário disse se sentir preso e agarrado na autarquia. O desenho ainda fornece outras informações que merecem destaque, como a necessidade de entender o que prende esse entrevistado e o que representa esse peso que ele carrega, além de perceber que suas mãos estão atadas.

Esse aspecto evidencia traços da administração burocrática presentes na autarquia estudada. Conforme Bresser-Pereira (2001), o modelo burocrático trouxe alguns privilégios em relação à aposentadoria e à estabilidade adquirida com os concursos públicos (BRESSER-PEREIRA, 2001). Assim, a questão da estabilidade proporcionada pelo concurso público é um aspecto da gestão tradicional que ainda tem vigorado na entidade analisada. A percepção semelhante do entrevistado 15 , que é o entrevistado com menos tempo de casa, é traduzida por meio do desenho apresentado na Figura 3.

\section{Figura 3 - Desenho do entrevistado 15}

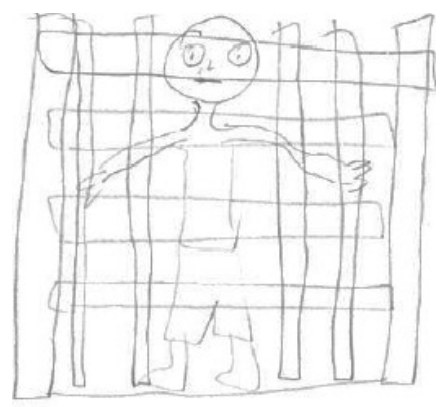

Entretanto, o entrevistado 15 atribui sua prisão às normas de conduta e regulamentos impostos pela gestão, em que não existe equilíbrio e bom senso, aspectos amparados pelos conceitos de Schikmann (2010) sobre a rigidez imposta 
pela legislação, que limita a cultura de inovação. Para esse entrevistado, a pessoa que entra no serviço público se vê em uma situação amarga:

O concurso público funciona como uma âncora. Se você está no mercado, se não está dando certo, você vai ao encontro de outro, mas no serviço público tem a estabilidade e é isso que te segura. No serviço público vê-se que a maioria dos salários não são "salários milionários", então pela utopia da estabilidade, a pessoa fica numa situação amarga (E15).

Assim, percebe-se que, mesmo com as mudanças percebidas na área de gestão de pessoas, o setor público tem características intrínsecas, que limitam a flexibilidade.

A análise dos desenhos também evidenciou que os funcionários sentem que existe uma distância, uma separação entre eles e a gestão de pessoas, conforme explicitado pelo entrevistado E12 na Figura 4 e no seu relato de entrevista: "Para mim a gestão de pessoas é como uma nuvem: está distante de mim".

\section{Figura 4 - Desenho do entrevistado 12}

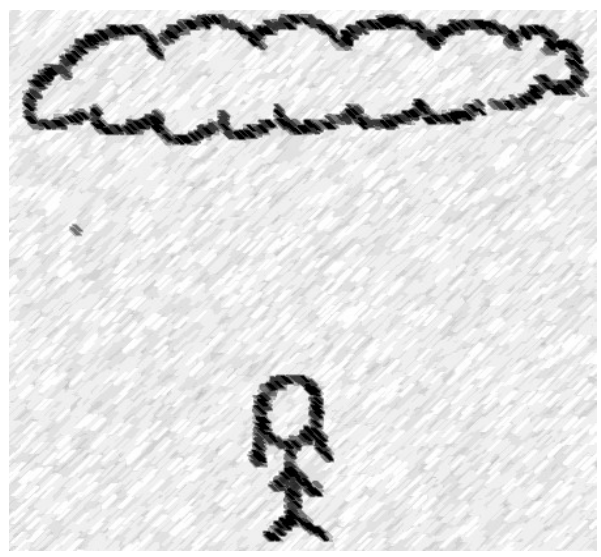

Esse sentimento está em discordância com o modelo de gestão de pessoas orientado para resultados, que tem como premissa o alinhamento entre capital humano e estratégia da organização, aspecto que sugere proximidade entre a gestão de pessoas e as pessoas da organização, na intenção de orientá-las na busca do resultado. Essa separação insinua um traço intrínseco à burocracia, que é a impessoalidade (COSTA, 2008).

Essa impessoalidade é reforçada pelo desenho, no qual o entrevistado aparece com a face sem as características pessoais, o que traz o entendimento de que não sente valorização em relação à sua competência. Isso contradiz a gestão por competências, a qual sugere uma valorização que vai além de conhecimentos 
técnicos, considerando também as habilidades interpessoais, as capacidades cognitivas e de conduta, a percepção de si próprio, traduzindo em atitudes e valores os traços de personalidade ou caráter (AMARAL, 2006; LONGO, 2007). Esses traços não impressos no desenho conduzem a uma ideia de não existência da valorização das competências na autarquia.

O desenho do entrevistado 13 (Figura 5) corrobora a interpretação da distância e da falta de características pessoais, acrescentando ainda a concepção de que existe um pequeno grupo controlador, como no Estado patrimonial. O entrevistado não enxerga a existência da gestão de pessoas, e sim um pequeno grupo que controla os funcionários: "Eu acho que não tem gestão de pessoas, existe uma ou duas pessoas que controlam o restante. Falta muito ainda" (E13).

\section{Figura 5 - Desenho do entrevistado 13}

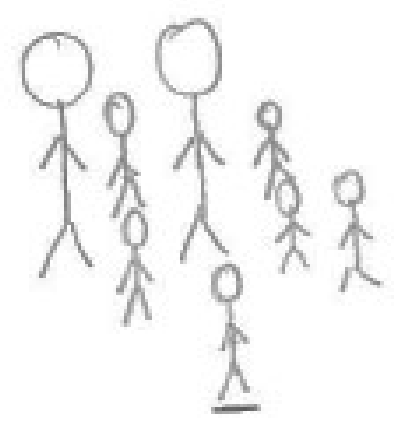

Essa diferença entre os grupos pode ser vista no desenho, onde dois indivíduos possuem tamanho maior que os outros. Mesmo aparentemente estando em um mesmo grupo, dois são maiores, enquanto a maioria tem tamanho menor. Interessante ressaltar que nenhum dos indivíduos de tamanho menor consegue superar os grandes, o que sugere a prevalência da hierarquia, característica própria da administração burocrática (COSTA, 2008).

Correlacionada a essa visão, o desenho do entrevistado 11 completa a ideia exposta anteriormente pelos entrevistados 12 e 13, sobre a existência de um grupo pequeno privilegiado, e a distância entre esse grupo e os funcionários. 


\section{Figura 6 - Desenho do entrevistado 11}

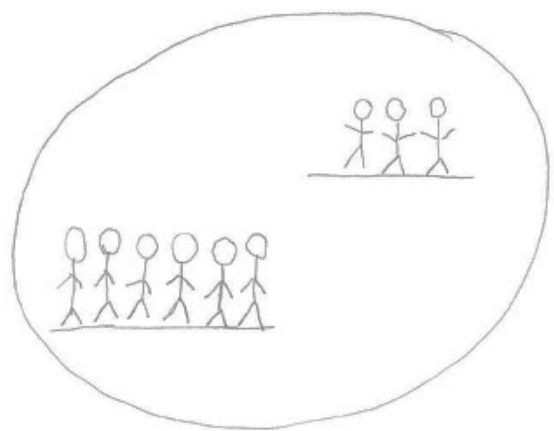

O conjunto de ideias expressas pelos funcionários confirma o que Schikmann (2010) destaca sobre a proteção, ou privilégio de cargos e funções, que são fatores que promovem um mecanismo limitador na busca por resultados.

Pelos desenhos construídos pelos funcionários, foi possível destacar algumas das características do setor público que se mantiveram mesmo com as mudanças desde o Estado patrimonial até a administração gerencial. Alguns desenhos apresentaram o favorecimento de certos grupos, o que remete ao Estado patrimonial, outros evidenciaram a rigidez da burocracia. Desse modo, é relevante analisar como os entrevistados (gestores e funcionários) percebem o planejamento de gestão de pessoas na autarquia.

\section{O planejamento de gestão de pessoas na autarquia}

Quando indagados sobre o que entendem como gestão estratégica de pessoas, as respostas dos entrevistados se concentraram em torno de uma ideia principal: alinhar os recursos humanos de acordo com os cargos existentes. Não foi apontada a inserção dessa gestão estratégica de pessoas em um plano superior, que é o planejamento estratégico da organização.

Sobre a existência de um planejamento estratégico da entidade, os depoimentos apontaram para um plano de atividades anual, que descreve os projetos de cada setor para o ano seguinte. Percebeu-se que esse plano é operacional, tanto pelo objetivo quanto pelo prazo a que se refere. Percebeu-se a inexistência de uma visão sistêmica em relação à gestão de pessoas, levando à compreensão de que o conceito de gestão estratégica está pautado nos processos internos da autarquia.

Observou-se, com os depoimentos, que a área de $\mathrm{RH}$ da autarquia é caracterizada como operacional, tendo como funções principais recrutamento, treinamento, avaliação de desempenho, desligamento, entre outras atividades relacionadas. 0 que vai à contramão da proposta da gestão estratégica, em que essa área deveria ser reestruturada, assumindo uma posição estratégica (AMARAL, 2006). Até mesmo 
mudanças no nível estratégico da autarquia, como a mudança de dirigente em 2016, não afetaram de forma significativa a forma com que a autarquia tem gerenciado seu capital humano.

Entretanto, os entrevistados consideram que o setor de $\mathrm{RH}$ tem evoluído. Aqueles que trabalham há mais de 15 anos na entidade afirmam que, quando foram admitidos, o setor de RH era um setor burocrático, um departamento de pessoal, que cuidava da folha de pagamento.

Quando eu entrei não tinha, agora que eles começaram a desenvolver os $\mathrm{RH}$ porque antes era só departamento pessoal. Vem evoluindo aos poucos, mas eu acho que ainda falta uma estruturação melhor (E11).

Assim, os entrevistados conseguem enxergar transformações na gestão de pessoas da entidade. Alguns relacionam a mudança à questão da implantação da ISO 9001. A Certificação ISO (International Organization for Standardization) estipula uma padronização do trabalho relacionado com um sistema de gestão da qualidade, sendo a ISO 9000 determinante de uma série de normas, entre essas a ISO 9001 (Mello et al., 2009). Outros consideram que o surgimento do Plano de Cargos, Carreiras e Salários (PCCS), a avaliação de desempenho e as pesquisas de clima organizacional são evidências de uma evolução da gestão de pessoas na organização.

Em relação às alterações ocasionadas pela implantação da ISO 9001, para a autarquia obter essa certificação, foram necessárias estruturações relacionadas a recursos humanos, como treinamentos, capacitações, conscientização; infraestrutura e ambiente de trabalho, além da definição da missão, visão e políticas de qualidade. Essas ações voltadas para a certificação ISO 9001 deram início a alguns procedimentos e rotinas que trouxeram uma percepção de desenvolvimento na gestão de pessoas na organização para atender aos requisitos da norma.

Quando eu entrei não existia isso, existia só um serviço de pessoal. Mas isso foi aperfeiçoado com a questão da ISO 9001, foram feitos muitos treinamentos com os funcionários, treinamentos técnicos de acordo com a área. Eu entendo que tem uma evolução muito grande (E1).

Entretanto, a partir dos relatos sobre a evolução da gestão de pessoas, surge uma reflexão que consiste em compreender se as alterações provocadas pela implantação da ISO 9001 estão sendo caracterizadas como evolução de forma imprópria. Conforme Longo (2007), a verdadeira mudança é aquela que consegue penetrar nas mentes dos indivíduos e se transferir para suas condutas. Assim, questiona-se até que ponto essas mudanças impactaram as condutas das pessoas, 
já que apenas as reestruturações organizacionais e a modernização tecnológica, por si sós, não são suficientes para mudar em profundidade o funcionamento das organizações públicas.

Os modelos de gestão estratégica de pessoas propõem o alinhamento entre os recursos humanos e os objetivos da entidade considerando essas características. Amaral (2006) sugere que é necessária uma mudança profunda no que tange ao mapeamento das competências requeridas e à reestruturação da área de RH, para que a organização tenha condições de alinhar seu capital humano às estratégias da organização. Sobre a existência de um modelo de gestão de pessoas, tanto líderes quanto funcionários acreditam que ainda não existe um modelo estruturado. Mas, afirmam que é um processo que está em desenvolvimento, sobre o qual é possível verificar evoluções percebidas pelos entrevistados. A partir da análise dos depoimentos, compreendeu-se que a gestão de pessoas não atua de forma estratégica na entidade, mantendo certa distância dos funcionários:

O setor de RH é muito fechado, introspectivo, é bem distante dos funcionários. Nas empresas onde trabalhei antes, havia uma comunicação melhor com os funcionários. A linha de comunicação era mais aberta (E15).

Percebeu-se também que existem mecanismos ligados à gestão de pessoas na autarquia que apresentam limitações e vantagens. Os principais mecanismos citados nas entrevistas foram o Plano de Cargos, Carreiras e Salários (PCCS) e a avaliação de desempenho. Ambos são vistos sob duas perspectivas, como benefícios e como entraves, conforme discutido nas seções seguintes.

\section{Gestão do emprego - práticas de recrutamento, seleção, manutenção e mobilidade}

A visão dos entrevistados sobre a gestão do emprego na autarquia foi marcada por muitos questionamentos relacionados ao perfil do profissional selecionado por meio de concurso público. Os entrevistados avaliam que essa forma de recrutamento e seleção retira a autonomia do gestor para selecionar pessoas de acordo com o perfil adequado a determinada atividade:

A pessoa só entra mediante concurso, às vezes você não vai colocar um profissional que você queira, você vai colocar o profissional que passou no concurso. E nem sempre necessariamente o profissional que passou vai ser um bom profissional (E7).

Os líderes sentem falta do poder de negociação, quando querem reter um talento, ou seja, evitar perder pessoas qualificadas. Muitos avaliam que não possuem autonomia para gerenciar suas equipes devido às restrições do Plano 
de Cargos e Salários (PCCS). O gestor se sente limitado, pois não pode oferecer incentivos salariais e profissionais visando à retenção dos talentos da organização.

Não é possível reter talentos aqui por conta desta burocracia do serviço público - "não pode isto, não pode aquilo". Eu poderia muito bem reter um talento, mas a burocracia me engessa. Na iniciativa privada, o gestor pode recompensar da forma que ele achar melhor (E9).

Percebe-se que a questão da rigidez da legislação é percebida como o maior aspecto limitador para a gestão do emprego na autarquia, uma vez que impede os gestores de valorizar e reter as pessoas como gostariam.

Uma grande dificuldade que temos hoje é a retenção de talentos porque hoje sabemos que muitos funcionários que ingressam aqui através de concursos estão estudando para outros concursos, e no momento que ele tem uma outra oportunidade no mercado, a autarquia se sente engessada em reter este talento. Às vezes ele é um profissional potencial, mas como não temos como cobrir a oferta recebida, então nós perdemos o funcionário (E5).

Mesmo que os depoimentos dos gestores apontem para a falta de autonomia na gestão de pessoas, o que contradiz um dos princípios da administração gerencial, para Coelho (2004) existe a possibilidade de superar essas limitações por meio do estímulo do sentimento de orgulho no serviço público. Além disso, há a possibilidade de se investir no desenvolvimento de pessoas, o que poderia contribuir para a retenção de talentos.

A discricionariedade que o gestor tem está atribuída à própria lei. A lei define até onde há uma flexibilidade para o gestor ir ou não, e isso realmente dificulta. As pessoas quando ingressam aqui já ingressam sabendo até onde elas podem ir (E6).

Além do incentivo ao orgulho no cargo (COELHO, 2004), outra forma de superar as limitações da gestão de pessoas no setor público consiste em focalizar nas lacunas existentes na legislação com o objetivo de utilizar a competência dos servidores, direcionando-os para os resultados (AMARAL, 2006). Verificou-se que a utilização dos espaços de manobra existentes na legislação é realizada na entidade.

Foi feita uma parceria com um instituto para contratar pessoas deficientes e eu acho que isso foi interessante, porque, por ser do setor público, a entidade tem a limitação do concurso público, então não tem como selecionar os candidatos. Como teve essa oportunidade de fazer a entrevista com essas pessoas, foi muito importante para ver que existem outras formas de ingressar funcionários aqui (E11). 
A gente tenta colocar isso na hora de fazer algum remanejamento. Procurase o melhor profissional para ser remanejado. Se a pessoa chegou numa gerência, numa diretoria, é porque nós estudamos os recursos humanos que temos, e estudamos quem mais se destaca. Nossa alternativa é esta: dentro do nosso quadro de funcionários, descobrir o talento das pessoas (E7).

O depoimento do entrevistado 11 expõe a flexibilidade encontrada pela entidade em contratar funcionários de forma alternativa ao concurso público por meio de uma parceria para a contratação de pessoas com necessidades especiais. O depoimento do entrevistado 7 mostra que, por meio da mobilidade interna, a migração dos funcionários entre as funções e setores é realizada de acordo com a competência demonstrada pelos mesmos. Essas estratégias evidenciam como é possível cruzar as barreiras impostas pela rigidez das normas, com o objetivo de flexibilizar o modelo de gestão de pessoas em prol do alcance de resultados.

Por outro lado, tem-se a falta de autonomia do gestor para demitir um funcionário se ele não está de acordo com o perfil procurado, pois a demissão só ocorre mediante processo administrativo.

Por ser do setor público, para demitir tem que montar um processo administrativo, verificar o que aconteceu, se vai gerar alguma punição conforme o regulamento de funcionários, então é mais trabalhoso. Ao contrário da empresa privada, em que, se o gerente não gostou do trabalho, a pessoa é demitida (E4).

Dessa forma, os gestores devem manter um funcionário em sua equipe, mesmo se considerarem que o mesmo não está gerando resultados. Conforme o entrevistado 10: "Se eu acho que uma pessoa não é tão eficiente, o máximo que eu posso fazer é não promovê-la".

Conclui-se, então, que os gestores se sentem limitados em três dimensões. A primeira delas se refere ao processo de seleção, já que não possuem autonomia em delinear o perfil profissional a ser selecionado. A segunda limitação se refere à retenção dos talentos. E, por último, há a questão dos processos de desligamento, que devem ocorrer mediante processos administrativos.

\section{Gestão das relações humanas}

Outro desafio relatado nos depoimentos refere-se à gestão das relações humanas. Estimular um clima de aceitação a mudanças e estimular as pessoas a enfrentarem novos desafios consiste em uma grande dificuldade para os gestores. Na opinião dos entrevistados, esse fato está relacionado à questão da estabilidade, que é uma barreira a essa postura de aceitar desafios, correr riscos. 
Em relação à gestão de pessoas, o maior desafio é a questão da zona de conforto, porque as pessoas não querem sair dessa zona de conforto. Motivar as pessoas a enfrentarem novos desafios, a correr riscos, e não falo de riscos financeiros não, é o risco de um projeto dar certo ou não. Só erra quem faz, e o funcionário público não quer errar e não quer fazer (E 10).

Extrair ou conseguir com que as pessoas deem o seu melhor mesmo trabalhando numa autarquia, mesmo tendo estabilidade (E3).

Os relatos revelam que os líderes têm a vontade de seguir uma estratégia de comprometimento, entretanto, esse desejo esbarra em mecanismos legais, como o Plano de Cargos, Carreiras e Salários (PCCS) e a estabilidade. A própria rigidez da legislação estimula a inércia gerencial (SCHIKMANN, 2010). Vale ressaltar que, sob o ponto de vista teórico, a implementação de um modelo de gestão por competências deve envolver uma mudança nas condutas dos indivíduos, o que não foi relatado nas entrevistas.

\section{A gestão do desempenho e da compensação}

A avaliação de desempenho foi um assunto constante em todas as entrevistas. Para a maior parte dos entrevistados, esse mecanismo representa uma forma de valorização das competências das pessoas, entretanto, as críticas se direcionam a seu funcionamento:

Tem a avaliação de desempenho, que eu acho que é um ganho, mas, do jeito que ela está hoje, tem algumas divergências, porque é complicado você colocar um valor, que o gerente que avalia o funcionário, então, dependendo da avaliação que ele faz, a pessoa vai ter aquela progressão ali, se ele não tiver assim, vai ser pelo tempo (E13).

O relato demonstra a impotência dos funcionários em relação aos gestores, no que tange à avaliação de desempenho. $O$ gestor tem discricionariedade para promover funcionários, porém não existe um parâmetro objetivo para padronizar essa avaliação.

Ainda assim, o surgimento da avaliação de desempenho é visto como um ganho, por representar uma forma de valorização do diferencial do funcionário em meio à rigidez da legislação. A avaliação de desempenho está ligada aos preceitos da administração gerencial, que visa dotar o gestor de maior autonomia e valorizar o capital humano das organizações (COSTA, 2008), assim como à ênfase no controle de resultados (MATIAS-PEREIRA, 2007).

A partir do momento que a pessoa investe no cargo, demonstrando um diferencial, mostra que o seu trabalho está tendo um retorno maior 
que a instituição esperava, com certeza será reconhecido na avaliação de desempenho e fará com que esta pessoa consiga um cargo de comissão, um cargo de confiança, dentro desse diferencial (E6).

A avaliação de desempenho na autarquia proporciona aos funcionários progressões na carreira. Foi considerado que o PCCS trouxe transparência em relação a valores, promoções, explicitando os valores das remunerações de todos os cargos, inclusive os comissionados. Entretanto, nas entrevistas foi possível perceber que, por outro lado, esse mecanismo limita a flexibilidade dos gestores e reduz a mobilidade dos funcionários dentro da entidade.

Eu acho que a nossa gestão é um pouco emperrada pela questão pública, porque na iniciativa privada você tem mais liberdade, então eu acho que a nossa fica um pouco a desejar por causa da burocracia do serviço público, porque, quando a gente tem um PCCS registrado no Ministério Público, engessa um pouco (E9).

Essa falta de liberdade foi relatada também no que tange à gestão da compensação. Percebeu-se, pelos relatos em 2013 e pela observação participante em 2016, que tanto líderes quanto funcionários têm se preocupado com a transformação do Regime Celetista para o Regime Jurídico Único. Essa mudança está tramitando judicialmente. Acredita-se que, caso ocorra essa mudança, muitos aspectos serão alterados na gestão de pessoas da autarquia, inclusive no que diz respeito à autonomia dos líderes.

De um lado, os funcionários esperam melhorias com essa mudança, principalmente relacionadas à aposentadoria. De outro lado, os líderes enxergam essa mudança como um retrocesso, principalmente devido à limitação na discricionariedade dos gestores e, consequentemente, a redução da autonomia dos mesmos. Para o entrevistado 10, essa mudança é prejudicial também para os funcionários, principalmente quando se trata de aumentos salariais.

Sendo uma autarquia federal, eu tenho muito mais liberdade, eu posso dar um aumento conforme o INPC (Índice Nacional de Preço ao Consumidor), e não tenho que dar satisfação para o Governo Federal porque o meu aumento aqui não afeta o Governo Federal ou os outros estados. Se eu tenho boa arrecadação e se eu economizo, posso repassar mais em forma de aumento para os funcionários, pelo fato de uma autarquia ser independente (E 10).

Observou-se que, no que tange às práticas de gestão de pessoas na autarquia, elas são permeadas por paradoxos. Ao mesmo tempo em que um mecanismo como o PCCS traz mais transparência, ele funciona como limitador. A avaliação 
de desempenho traz certa autonomia para o gestor, mas essa discricionariedade incomoda os funcionários. O mesmo acontece com a mudança para o RJU: vista como uma conquista pelos funcionários, no entanto representa mais limitação para os líderes. Assim, conclui-se que mesmo as evoluções trazidas pela administração gerencial se deparam com resistências típicas do setor público, o que será discutido nas Considerações finais.

\section{Considerações finais}

O objetivo deste trabalho foi analisar a percepção de gestores e funcionários acerca da gestão de pessoas em uma autarquia federal. O referencial teórico foi tecido com o intuito de contemplar a trajetória histórica da gestão pública no Brasil, com destaque para as reformas. Além disso, apresentou-se um aporte teórico sobre a gestão estratégica de pessoas no setor público, a gestão por competências e alguns estudos sobre práticas relacionadas à gestão de pessoas nesse setor.

O método escolhido para coletar os dados foi o de entrevistas semiestruturadas e a construção de desenhos. Os funcionários tinham liberdade para expressar por meio dos desenhos como se sentem em relação à gestão de pessoas da autarquia. Foi feita observação participante de forma suplementar. Com a análise dos desenhos, percebeu-se que a gestão de pessoas no setor público é carregada por características peculiares que limitam os ensejos de mudança e a busca por uma administração gerencial.

Não foi encontrada na autarquia uma gestão que estimule o desenvolvimento de seu capital humano, concordando com Coelho (2004) ao afirmar que no setor público não se encontra ainda um ambiente que estimule o desenvolvimento. Os relatos dos entrevistados se restringem à ferramenta de levantamento das necessidades de treinamento, notando uma ausência de práticas voltadas para esse aspecto. Este estudo converge ainda com o trabalho de Moura e Souza (2016), ao identificar a ausência da gestão estratégica e seus motivos, relacionados à prevalência de um setor de $\mathrm{RH}$ reativo e operacional e características peculiares que fazem com que existam restrições e limitações para a implementação de práticas próprias da administração gerencial no setor público.

Com isso, o entendimento de gestão estratégica de pessoas tanto para líderes quanto para os funcionários entrevistados esteve limitado ao contexto da autarquia estudada. Pelos depoimentos não foi percebida uma visão sistêmica relacionada à gestão de pessoas no setor público ou a inserção da gestão estratégica de pessoas em um planejamento estratégico.

Pelos depoimentos foi possível observar que a atual estrutura normativa impede a existência de um modelo de gestão estratégica no setor público. Os motivos da 
dificuldade em implementar essa gestão se relacionam sobretudo à rigidez da legislação e ao apego a formas tradicionais de gestão, o que limita a autonomia dos líderes em gerir pessoas. A dificuldade em delinear um perfil dos candidatos aos concursos antepara o mapeamento das competências. O dilema consiste na necessidade prevista para o setor público em reestruturar e modernizar suas práticas relacionadas à administração de recursos humanos, visto que tanto funcionários quanto líderes ficam à mercê da legislação.

A atualização dos dados obtida com a observação participante possibilitou compreender que, apesar das modificações legais, a gestão de pessoas da autarquia estudada vem sendo conduzida da mesma forma. As mudanças identificadas não se demonstram significativas a ponto de tornar a gestão de pessoas estratégica, já que se trata de mudanças operacionais com o intuito de responder a demandas de órgãos fiscalizadores. Isso reforça a posição reativa do RH (MourA; SouzA, 2016). Notou-se também que o debate sobre a transformação de Regime Celetista para Regime Jurídico Único ganhou força e, enquanto os funcionários têm a expectativa de melhorias, os líderes têm receio de perder ainda mais a autonomia com essas mudanças.

Como limitação da pesquisa, tem-se a dificuldade de generalização dos resultados, extrapolando o contexto da autarquia, de modo que estes não seriam suficientes para apontar uma tendência geral na administração pública. Assim, é indicado estudar as demais organizações desse setor, embora as particularidades da autarquia estudada corroborem a literatura sobre o tema que questiona a existências de um sistema meritocrático de gestão de pessoas no funcionalismo público.

A técnica de pesquisa pela construção de desenhos possibilitou ir além daquilo descrito pela literatura especializada sobre a gestão de pessoas no setor público. A partir dos desenhos, podem-se investigar empiricamente os dilemas cotidianos, as vontades individuais suprimidas quanto à carreira e ao desenvolvimento dos servidores públicos, o distanciamento da política e dos modelos de gestão de pessoas com as práticas da autarquia, entre outras limitações que não seriam detectadas da mesma forma por meio de entrevistas semiestruturadas. Portanto, uma proposta para futuros estudos seria a utilização dessa técnica em outras amostras, buscando compreender outros aspectos subjetivos que refletem as percepções de funcionários e gestores sobre a gestão estratégica de pessoas no setor público. 


\section{Referências bibliográficas}

AMARAL, R. M. Gestão de pessoas por competências em organizações públicas. In:

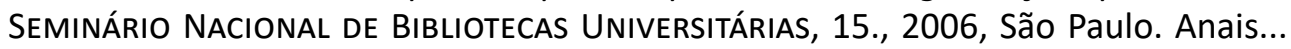
São Paulo: Universidade Federal de São Carlos (UFSCar), 2006.

ANTONELlo, C. S.; PANTOJA, M.J. Aprendizagem e o desenvolvimento de competências. In: PAntoja, M. J.; CAMÕES, M. R. S.; Bergue, S. T. (Orgs.). Gestão de pessoas: bases teóricas e experiências no setor público. Brasília: Enap, 2010.

BARBIERI, U. F. Gestão de pessoas nas organizações: práticas atuais sobre o RH estratégico. São Paulo: Atlas, 2012.

BARBOSA, L. Meritocracia à brasileira: o que é desempenho no Brasil?. Revista do Serviço Público, Enap, v. 47, n. 3, p. 59-102, set-dez. 1996.

BARDIN, L. Análise de conteúdo. Lisboa: Edições 70, 2002. (Obra original publicada em 1977).

Barros, A. J. P.; Lehfeld, N. A. S. Projeto de pesquisa: propostas metodológicas. 5. ed. Petrópolis: Vozes, 1997.

BLONSKI, F. et al. O controle gerencial na perspectiva do New Public Management: o caso da adoção do Balanced Scorecard na Receita Federal do Brasil. Administração Pública e Gestão Social, v. 9, n. 1, p. 15-30, 2017.

BRASIL. Decreto no 200, de 25 de fevereiro de 1967. Dispõe sobre a organização da Administração Federal, estabelece diretrizes para a Reforma Administrativa e dá outras providências. Brasília, DF, 25 fev. 2001.

. Decreto no 5.707, de 23 de fevereiro de 2006. Institui a Política e as Diretrizes para o Desenvolvimento de Pessoal da administração pública federal direta, autárquica e fundacional, e regulamenta dispositivos da Lei no 8.112, de 11 de dezembro de 1990. Diário Oficial da República Federativa do Brasil, Brasília, DF, 24 de fevereiro de 2006.

Decreto no 7.133, de 19 de março de 2010. Regulamenta os critérios e procedimentos gerais a serem observados para a realização das avaliações de desempenho individual e institucional e o pagamento das gratificações de desempenho.

[Internet]. Brasília; 2010 [citado 2011 ago. 22]. Disponível em: http://www.planalto. gov.br/ccivil_03/_ato2007-2010/2010/decreto/d7133.htm Acesso em: 10 de jan de 2017.

BRESSER-PEREIRA, L. C. Reforma do Estado para a cidadania. Rio de Janeiro: FGV, 1998.

Brasil: um século de transformações. In: PinheIRo, P. S.; WILHEIM, J.; SACHS, I. (Orgs.). Brasil: um século de transformações. S. Paulo: Cia. Das Letras, 2001.

. Do Estado patrimonial ao gerencial. Revista do Serviço público, v. 120, n. 1,p.7-40, jan-abr. 1996.

CAMARGO, E. J. B. et al. Gestão de pessoas na administração pública federal: análise dos modelos adotados no período 1995 a 2010. Revista Interdisciplinar de Gestão Social, v. 5, n. 1, p. 63-87, 2016. 
CASTOR, B. V. J.; JosÉ, H. A. A. Reforma e contra-reforma: a perversa dinâmica da administração pública brasileira. Revista de Administração Pública, Rio de Janeiro, v. 32, n. 6, p. 97-111, nov./dez. 1998.

CAVALCANTE, P. L. Orçamento por desempenho: uma análise comparativa do modelo de avaliação dos programas governamentais no Brasil e nos Estados Unidos. REGE Revista de Gestão, v. 17, n. 1, p. 13-25, 2010.

Coelho, E. M. Gestão do conhecimento como sistema de gestão para o setor público. Revista do Serviço Público (RSP), v. 55, n. 1 e 2, p. 89-115, jan./jun. 2004.

COSTA, F. L. Brasil: 200 anos de Estado; 200 anos de administração pública; 200 anos de reformas. Revista de Administração Pública - Rio de Janeiro, v. 42, n. 5, p. 82974, 2008.

Goode, W. J.; HATT, P. K. Métodos em pesquisa social. 7. ed. São Paulo: Nacional, 1979.

LAKATOS, E. M.; MARConI, M. A. Metodologia científica. 6. ed. São Paulo: Atlas, 2011. LONGO, F. Mérito e flexibilidade: a gestão de pessoas no setor público. São Paulo: Fundap, 2007.

MASCARENHAS, A. O. Gestão estratégica de pessoas: evolução, teoria e crítica. São Paulo: Cengage Learning, 2008.

Matias-PereirA, J. Manual de gestão pública contemporânea. São Paulo: Atlas, 2007.

Mello, C. H. P.; Silva, C. E. S.; TURRIONI, J. B. ISO 9001: 2008: sistema de gestão da qualidade para operações de produção e serviços. São Paulo: Atlas, 2009.

MourA, A. L. N.; SouzA, B. C. Gestão estratégica de pessoas na administração indireta do setor público federal: na prática, ainda um discurso. Revista do Serviço Público, v. 67, n. 4, p. 575-602, 2016.

Nascimento, A. L.; Emmendoerfer, M.; GaVA, R. Comprometimento no trabalho de gestores públicos em uma autarquia estadual no Brasil. Revista do Serviço Público, v. 65, n. 2, p. 199-226, 2014.

Nogueira, R. P.; SANTANA, J. P. Human resources management and public sector reforms: trends and origins of a new approach. Discussion Paper, n. 115. Brasília: Ipea, jan. 2015. Disponível em: < http://migre.me/vcUAg >. Acesso em: 06 set, 2016.

OdElIUS, C. C.; SANTOS, P. Avaliação de desempenho individual na administração pública federal: aspectos intervenientes no processo e nos resultados. Revista Economia \& Gestão, v. 7, n. 15, p. 10-30, 2007.

PACHECO, R. S. Mensuração de desempenho no setor público: os termos do debate. Cadernos Gestão Pública e Cidadania, v. 14, n. 55, p. 149-161, 2009.

PeCl, A.; Pieranti, O. P.; Rodrigues, S. Governança e New Public Management: convergências e contradições no contexto brasileiro. Revista O\&S: Organizações e Sociedade, v. 15, n. 46, p. 39-55, jul./set. 2008.

PETERS, B. G. Os dois futuros do ato de governar: processos de descentralização e recentralização no ato de governar. Revista do Serviço Público, v. 59, n. 3, p. 289307, 2008. 
Richardson, R. J. Pesquisa social: métodos e técnicas. São Paulo: Atlas, 1999. 334 p. SALLES, M. A. S. D.; VILLARDI, B. Q. O desenvolvimento de competências gerenciais na prática dos gestores no contexto de uma IFES centenária. Revista do Serviço Público, v. 68, n. 2, p. 467-492, 2017.

SCHIKMANN, R. Gestão estratégica de pessoas: bases para a concepção do curso de especialização em gestão de pessoas no serviço público. In: CAMÕES, M. R. de S.; PANTOJA, M. J.; BERGUE, S. T. (Orgs.). Gestão de pessoas: bases teóricas e experiências no setor público. Brasília: Enap, 2010.

SECCHI, L. Modelos organizacionais e reformas da administração pública. Revista de Administração Pública, RAP-FGV, v. 43, n. 2, p. 347-369, 2009.

SILVA, F. M.; MELLO, S. P. T. A implantação da gestão por competências: práticas e resistências no setor público. Revista Eletrônica de Administração e Turismo-ReAT, v. 2, n. 1, p. 110-127, 2013.

SILVA, F. M.; MELLO, S. P. T. A noção de competência na gestão de pessoas: reflexões a partir de casos do setor público. Revista do Serviço Público, v. 62, n. 2, p. 167-183, 2011.

TıNoco, D. S. A influência do novo gerencialismo público na política de educação superior. Interface, Natal, v. 10, n. 1, p. 4-15, 2013.

VergaRA, S. C. A utilização da construção de desenhos como técnica de coleta de dados. In: VIEIRA, Marcelo Milano Falcão; ZouAIN, Deborah Moraes (Orgs.). Pesquisa qualitativa em administração - teoria e prática. Rio de Janeiro: FGV, 2005.

\section{Luana Jéssica Oliveira Carmo}

Mestrado em andamento em Administração pelo Programa de Pós-Graduação em Administração do Centro de Educação Tecnológica de Minas Gerais (Cefet/MG). Contato: luanajeoli@gmail.com

\section{Lilian Bambirra de Assis}

Doutora em Administração pela Universidade Federal de Minas Gerais (UFMG).Atualmente é professora do Centro de Educação Tecnológica de Minas Gerais (Cefet/MG). Contato: lilianbassis@hotmail.com

\section{Mariana Geisel Martins}

Mestre em Administração pelo Programa de Pós-Graduação em Administração do Centro de Educação Tecnológica de Minas Gerais (Cefet/MG). Contato: marianagmartins@hotmail.com

\section{Cristina Camila Teles Saldanha}

Mestrado em andamento em Administração Pública pela Fundação João Pinheiro (FJP/MG). Contato: cristina.c.t.saldanha@gmail.com

\section{Patrícia Albuquerque Gomes}

Mestrado em andamento em Administração pelo Programa de Pós-Graduação em Administração do Centro de Educação Tecnológica de Minas Gerais (Cefet/MG). Contato: gomespatriciaadm@gmail.com 